\title{
A retrospective investigation of the effect of tranexamic acid application and tourniquet duration on postoperative bleeding amount in patients undergoing total knee arthroplasty
}

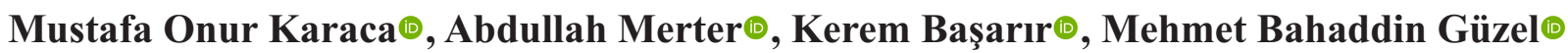

Department of Orthopaedics and Traumatology, Ankara University Faculty of Medicine, Ankara, Turkey

\begin{abstract}
Objectives: It is aimed to investigate the effect of tourniquet and tranexamic acid (TXA) on the amount of perioperative bleeding in patients undergoing total knee arthroplasty.

Methods: One hundred and ninety-three patients included in the study. The patients included in the study were divided into 4 groups. Group $1(\mathrm{n}=78)$ was determined as the patient group with long-term tourniquet application, but without additional application and was accepted as the control group. Group 2 ( $\mathrm{n}=40)$ was the long-term tourniquet and intravenous (IV) TXA applied group, Group $3(n=40)$ was the long-term tourniquet and intra-articular TXA applied group, and Group $4(n=35)$ was the short-term tourniquet (only in the cementing phase) and IV TXA applied group. The difference between groups according to use of a tourniquet during the operation, the method and dose of TXA, the amount of postoperative blood transfusion, the amount of drained blood, the length of hospital stay, and complications were investigated.

Results: The largest Hemoglobin (Hb) and Hematocrit (Hct) decreases were found in Group $1(3.39 \pm 0.92$ $\mathrm{g} / \mathrm{dl}$ and $10.8 \%$, respectively). Also the highest drainage (median $350 \mathrm{ml}$ ), transfusion (16.7\%), length of hospital stay (mean $4.51 \pm 1.07$ days) and estimated blood loss (median $1559.8 \mathrm{ml})$ were in Group $1(p<0.05)$. The lowest $\mathrm{Hb}$ decrease (mean $2.95 \pm 0.68 \mathrm{~g} / \mathrm{dl}$ ) and lowest drainage (median $150 \mathrm{ml}$ ) was seen in group 3 and the lowest length of hospital stay (mean $3.89 \pm 0.8$ days) in group $4(p<0.05)$.

Conclusions: The use of TXA was shown to lead to a reduction in $\mathrm{Hb}$ and Hct, the amount of blood drained after surgery, and the length of hospital stay. The use of TXA may be a good option for bleeding control in patients undergoing total knee arthroplasty.

Keywords: Tranexamic acid, arthroplasty, tourniquets, drains
\end{abstract}

$\mathrm{T}$ Total knee arthroplasty is among the current treatment options for advanced-stage gonarthrosis [13]. In the literature, it has been reported that the average amount of bleeding in total knee arthroplasty operations is between $800-1800 \mathrm{ml}[4,5]$. Blood transfusion applied due to bleeding prolongs both the reha- bilitation period and the length of hospital stay [6]. It also causes severe complications such as transfusion reaction, infection, metabolite imbalances, hemolysis, and immune system inhibition [7-9].

In total knee arthroplasty, a tourniquet is used to avoid complications related to blood transfusion. Stud- 
ies have shown that bleeding is less in cases where a tourniquet was used during total knee arthroplasty [2, 3]. However, it has also been shown that tourniquet use has complications such as quadriceps weakness, postoperative hip pain, local inflammation, and muscle damage [10-12]. Therefore, short-term use of a tourniquet (at the cementing stage) has been examined. Postoperative pain, swelling, and limitation of movement are less common in patients in whom short-term tourniquets are applied [10, 13-16].

Due to the complications seen in the use of a tourniquet, the use of antifibrinolytic agents has been given prominence in recent years to reduce bleeding $[17,18]$. Tranexamic acid (TXA) is one of these agents. It shows antifibrinolytic activity by inactivating plasminogen [19]. Tranexamic acid can be administered in a number of different ways (oral, intravenous, intra-articular). Although there are studies showing that each method is effective in reducing bleeding, which method and which dose are most effective in patients with total knee arthroplasty remain controversial $[1,6]$.

The present study aims to investigate the effect of tourniquet and TXA on the amount of perioperative bleeding in patients undergoing total knee arthroplasty, in addition to which, the efficacy difference between intravenous and intraarticular administrations of TXA is evaluated.

\section{METHODS}

In the university hospital where the study was conducted, a total of 245 cases of patients, who had undergone total knee arthroplasty between May 2014 and June 2015, were retrospectively scanned from the hospital archives. Patients with anemia $(<12 \mathrm{~g} / \mathrm{L}$ for females, $<13 \mathrm{~g} / \mathrm{L}$ for males) $(\mathrm{n}=10)$, comorbid disease (kidney dysfunction, cardiovascular disease, cerebrovascular disease, thromboembolic disease $)(n=9)$, body mass index $(B M I)>50 \mathrm{~kg} / \mathrm{m}^{2}(\mathrm{n}=7)$, tranexamic acid allergy (TXA) $(\mathrm{n}=1)$, advanced deformity before surgery (flexion deformity $>30^{\circ}$, varus and/or valgus deformity $\left.>30^{\circ}\right)(\mathrm{n}=12)$, and bilateral total knee arthroplasty $(n=13)$ were excluded from the study.

The information of 193 patients included in the study such as age, gender, side, Body Mass Index
(BMI), American Society of Anesthesiologists (ASA) category, preoperative and postoperative hemoglobin $(\mathrm{Hb})$, hematocrit (Hct) values, etiology of osteoarthrosis (osteoarthritis, rheumatoid arthritis, post-traumatic arthritis or osteonecrosis) was obtained from the hospital registry system. The use of a tourniquet during the operation, the method and dose of TXA, the amount of postoperative blood transfusion, the amount of drained blood, the length of hospital stay, and complications were also reviewed in the hospital registry system.

All patients were operated in the same clinic by two surgeons using the same surgical method. In the group of patients in grouop 1, 2 and 4, the tourniquet was inflated just before the incision to $100 \mathrm{~mm} \mathrm{Hg}$, more than the systemic systolic blood pressure of the patient. The tourniquet was deflated immediately after the incision was closed. In group 3, the tourniquet was inflated before the application of cement and removed just before the wound was closed when the cement had hardened. Intravenous (IV) TXA application was performed just before the incision with $10-15 \mathrm{mg} / \mathrm{kg}$ in $100 \mathrm{cc}$ saline solution, and intra-articular application was performed by applying $2 \mathrm{~g}$ TXA into the joint after the capsule was closed. None of the patients received TXA after surgery. Electrocautery was used for bleeding control, but no other local chemical agents were used. While the knee was in the $90^{\circ}$ flexion position and the incision was being closed, subcutaneous suturing was applied with a monofilament suture material, with a topical skin adhesive (Dermabond; Ethicon) then used. In all cases, drains were routinely applied. In patients undergoing intra-articular TXA, the drain was clamped for two hours. All patients were treated with $3 \times 1 \mathrm{~g}$ IV cefazolin sodium until the drain was removed after surgery. Celecoxib, ketorolac (max 2 doses), hydrocodone and acetaminophen were used for pain control and tramadol after surgery. Quadriceps strengthening, active and passive range of motion and walking exercises began on the first day after surgery. $\mathrm{Hb}$ and Hct control were performed on all patients undergoing arthroplasty on day 0 , day 1 , and day 3 . Blood transfusion was applied to patients who were $\mathrm{Hb}<7 \mathrm{~g} / \mathrm{dl}$ or $\mathrm{Hb}<8 \mathrm{~g} / \mathrm{dl}$ and symptomatic.

The patients included in the study were divided into 4 groups according to the tourniquet duration and TXA administration method. Group $1(\mathrm{n}=78)$ was determined as the patient group with long-term tourni- 
quet application, but without additional application and was accepted as the control group. Group 2 ( $\mathrm{n}=$ 40) was the long-term tourniquet and IV TXA application just before the incision with $10-15 \mathrm{mg} / \mathrm{kg}$ in 100 cc saline solution, Group $3(n=40)$ was the long-term tourniquet and intra-articular $2 \mathrm{~g}$ TXA into the joint after the capsule was closed group, and Group 4 ( $\mathrm{n}=$ 35) was the short-term tourniquet (only in the cementing phase) and IV TXA application just before the incision with $10-15 \mathrm{mg} / \mathrm{kg}$ in $100 \mathrm{cc}$ saline solution.

All reported research involving "Human beings" conducted in accordance with the principles set forth in the Helsinki Declaration 2008. This study was carried out with the permission of the ethics committee of the hospital where it was conducted dated 16.06.2015; No. 10-420-15 of. The patients and/or their families were informed that data would be submitted for publication, and gave their consent.

\section{Statistical Analysis}

The analysis of the data was carried out using the SPSS for Windows 25 package program. Descriptive statistics were shown as mean \pm standard deviation for variables with normal distribution, and median (min max) for non-distributed variables, while nominal variables were expressed as number of cases and (\%). While the variance analysis (ANOVA) test was used for the significance of the difference between the groups in terms of averages, the Fisher's Least Significant Difference (LSD) was used for the significance of the difference in terms of median values and the Dunn's Test was used for the post-hoc analysis. Nominal variables were evaluated by the Pearson ChiSquare test. The results were considered statistically significant for $p<0.05$.

\section{RESULTS}

The mean age of 193 patients ( 163 females and 30 males) included in the study was $67.8 \pm 7.9$ years. One hundred and one patients were operated on the right knee and 92 patients on the left and the mean BMI of the patients was $31.1 \pm 4.7 \mathrm{~kg} / \mathrm{m}^{2}$. Distribution of demographic data by groups and osteoarthritis etiologies are shown in Table 1. The brands and models of the

Table 1. Demographic characteristics of the patients

\begin{tabular}{|c|c|c|c|c|c|}
\hline & $\begin{array}{l}\text { Group } 1 \\
(n=78)\end{array}$ & $\begin{array}{l}\text { Group 2 } \\
(\mathrm{n}=40)\end{array}$ & $\begin{array}{l}\text { Group } 3 \\
(n=40)\end{array}$ & $\begin{array}{l}\text { Group } 4 \\
(n=35)\end{array}$ & $p$ value \\
\hline & Mean \pm SD. & Mean \pm SD. & Mean \pm SD. & Mean \pm SD. & \\
\hline \multirow[t]{2}{*}{ Age (years) } & $66.6 \pm 7.8$ & $66.9 \pm 8.1$ & $67.9 \pm 6.1$ & $71.1 \pm 9.6$ & $0.047^{\mathrm{a}}$ \\
\hline & n (\%) & n $(\%)$ & n $(\%)$ & n $(\%)$ & \\
\hline \multicolumn{6}{|l|}{ Sex } \\
\hline Female & $67(85.9)$ & $36(90.0)$ & $32(80.0)$ & $28(80.0)$ & $0.533^{\mathrm{p}}$ \\
\hline Male & $11(14.1)$ & $4(10.0)$ & $8(20.0)$ & $7(20.0)$ & \\
\hline \multicolumn{6}{|l|}{ Side } \\
\hline Right & $41(52.6)$ & $23(57.5)$ & $17(42.5)$ & $20(57.1)$ & $0.512^{\mathrm{p}}$ \\
\hline \multirow[t]{2}{*}{ Left } & $37(47.4)$ & $17(42.5)$ & $23(57.5)$ & $15(42.9)$ & \\
\hline & $\begin{array}{c}\text { Median } \\
\text { (Min-Max) }\end{array}$ & $\begin{array}{c}\text { Median } \\
\text { (Min-Max }\end{array}$ & $\begin{array}{c}\text { Median } \\
\text { (Min-Max }\end{array}$ & $\begin{array}{c}\text { Median } \\
\text { (Min-Max }\end{array}$ & \\
\hline BMI & $30.4(20.7-44)$ & $29.7(22.7-48.2)$ & $31.6(25.3-44.9)$ & $31.2(21.7-48.4)$ & $0.230^{\mathrm{k}}$ \\
\hline $\begin{array}{l}\text { Starting } \\
\text { hemoglobin }(\mathrm{g} / \mathrm{dL})\end{array}$ & $13.2(10.7-16.1)$ & $13.6(10.2-15.6)$ & $13.2(10.4-16.3)$ & $13.6(12.2-16.3)$ & $0.201^{\mathrm{k}}$ \\
\hline $\begin{array}{l}\text { Starting hematocrit } \\
(\mathrm{g} / \mathrm{dL})\end{array}$ & $39.9(32.8-49.4)$ & $40.8(30.3-48.8)$ & $39.7(33.3-49.3)$ & $40.4(36.8-49)$ & $0.518^{\mathrm{k}}$ \\
\hline
\end{tabular}


Table 2. Knee replacement systems

\begin{tabular}{|c|c|c|c|c|c|}
\hline & $\begin{array}{c}\text { Biomet } \\
\text { Vanguard }^{\circledR}\end{array}$ & $\begin{array}{c}\text { Depuy P.F.C. } \\
\text { Sigma }^{\circledR}\end{array}$ & $\begin{array}{c}\text { Exactech } \\
\text { Optetrak }^{\circledR} \\
\end{array}$ & $\begin{array}{c}\text { Smith \& Nephew } \\
\text { Genesis II }^{\circledR}\end{array}$ & $\begin{array}{r}\text { Biomet } \\
\text { ROCC }^{\circledR} \\
\end{array}$ \\
\hline Group 1 & 22 & 19 & 25 & 11 & 1 \\
\hline Group 2 & 27 & 13 & - & - & - \\
\hline Group 3 & 24 & 8 & - & 4 & 4 \\
\hline Group 4 & 20 & 15 & - & - & - \\
\hline
\end{tabular}

implants applied to the patients are shown in Table 2 .

The largest $\mathrm{Hb}$ and Hct decreases were found in Group 1 (3.39 $\pm 0.92 \mathrm{~g} / \mathrm{dl}$ and $10.8 \%$, respectively). Similarly, the highest drainage (median $350 \mathrm{ml}$ ), transfusion (16.7\%), length of hospital stay (mean $4.51 \pm$ 1.07 days) and estimated blood loss (median 1559.8 $\mathrm{ml}$ ) were in Group 1, and this difference was statistically significant $(p<0.05)$. The lowest $\mathrm{Hb}$ decrease (mean $2.95 \pm 0.68 \mathrm{~g} / \mathrm{dl}$ ) and the lowest drainage was found in Group 3 (median $150 \mathrm{ml}$; range 50 to 500 $\mathrm{ml}$ ), and the lowest length of hospital stay (mean 3.89 \pm 0.8 days) in group 4 . This difference was statistically significant $(p<0.05)$. The distribution of the evaluation criteria by groups and comparison of the groups with each other are shown in Table 3.

\section{DISCUSSION}

A tourniquet is routinely used by many surgeons in total knee arthroplasty surgery. The application of tranexamic acid has become increasingly popular in recent years [17, 18]. Many studies in the literature show that it reduces bleeding in arthroplasty surgeries. In a prospective randomized controlled study conducted by Huang et al. [2] with 150 patients in 2017, patients who received multiple doses of oral and IV TXA were found to have fewer instances of hidden blood loss, swelling and pain, and lower inflammatory markers compared to patients in whom only a tourniquet was applied. In a prospective randomized study by Santias et al. [20], 2 g TXA/50 ml topical admin-

\section{Table 3. Comparison of differences in blood loss}

\begin{tabular}{|c|c|c|c|c|c|c|}
\hline & $\begin{array}{c}\text { Max hb } \\
\operatorname{drop}(g / d L)\end{array}$ & $\begin{array}{c}\text { Max htc } \\
\text { drop (\%) }\end{array}$ & $\begin{array}{c}\text { Drained } \\
\text { blood (ml) }\end{array}$ & Transfusions & $\begin{array}{l}\text { Length of } \\
\text { stay (days) }\end{array}$ & $\begin{array}{l}\text { EVB calculated } \\
\text { blood loss }\end{array}$ \\
\hline & Mean \pm SD & $\begin{array}{c}\text { Median } \\
\text { (Min-Max }\end{array}$ & $\begin{array}{c}\text { Median } \\
\text { (Min-Max) }\end{array}$ & n $(\%)$ & Mean \pm SD & $\begin{array}{c}\text { Median } \\
\text { (Min-Max) }\end{array}$ \\
\hline Group 1 & $3.39 \pm 0.92$ & $10.8(4.1-17.8)$ & $350(20-1000)$ & $13(16.7 \%)$ & $4.51 \pm 1.07$ & $1559.8(468.6-3620.5)$ \\
\hline Group 2 & $2.85 \pm 0.99$ & $8.6(2.9-15)$ & $285(50-500)$ & $3(7.5 \%)$ & $4.10 \pm 0.9$ & $1077.6(393.2-2065.1)$ \\
\hline Group 3 & $2.80 \pm 0.67$ & $8.9(5.2-12.7)$ & $150(50-500)$ & $4(10 \%)$ & $3.97 \pm 0.7$ & $1273.4(614.5-2459.4)$ \\
\hline Group 4 & $2.95 \pm 0.68$ & $8.8(4.4-11.2)$ & $225(75-425)$ & $2(5.7 \%)$ & $3.89 \pm 0.8$ & $1212.2(638.2-2369.2)$ \\
\hline$p$ value & $<0.001^{\mathrm{a}}$ & $<0.001^{\mathrm{k}}$ & $<0.001^{\mathrm{k}}$ & $0.337^{p}$ & $0.002^{\mathrm{a}}$ & $<0.001^{\mathrm{k}}$ \\
\hline G1-G2 & 0.029 & $<0.001$ & 0.018 & ns & 0.183 & $<0.001$ \\
\hline G1-G3 & 0.009 & $<0.001$ & $<0.001$ & $>0.05$ & 0.066 & 0.009 \\
\hline G1-G4 & 0.402 & $<0.001$ & $<0.001$ & $>0.05$ & 0.008 & 0.001 \\
\hline G2-G3 & 0.774 & 0.705 & 0.001 & $>0.05$ & 0.553 & 0.224 \\
\hline G2-G4 & 0.626 & 0.948 & 0.202 & $>0.05$ & 0.327 & 0.589 \\
\hline G3-G4 & 0.445 & 0.764 & 0.049 & $>0.05$ & 0.683 & 0.525 \\
\hline
\end{tabular}

${ }^{a}$ One Way ANOVA Test, Post Hoc Test = Fisher's Least Significant Difference (LSD), ${ }^{\text {pPearson chi-square test, }{ }^{\mathrm{k}} \mathrm{Kruskal}-}$ Wallis test, Post Hoc Test $=$ Dunn's Test, $\mathrm{SD}=$ Standard deviation, Min $=$ Minimum, Max $=\mathrm{Maximum}, \mathrm{G}=$ group, Hb =hemoglobin, Htc = hematocrit, Tq = tourniquet, iv = intravenous, ia = intraarticular, Group1 = Tourniquet only, Group2 = Tq and iv TXA, Group $3=$ Tq and ia TXA), Group $4=$ Tq cementing and iv TXA 
istration has been shown to reduce the amount of postoperative bleeding without increasing thromboembolic risks in primary cemented total knee arthroplasty cases. Meng et al. [21] made an evaluation especially for an obese patient group, where it was difficult to use a tourniquet. They showed that the use of TXA reduced bleeding and concluded that obese patients benefit more from TXA than individuals of normal body weight [21]. In their study, which included 180 patients, Tzatzairis et al. showed that the administration of 3 doses of IV TXA significantly reduced allogeneic blood transfusion and blood loss in patients who underwent arthroplasty without tourniquet [22]. In the present study, less significant $\mathrm{Hb}$ and Hct reductions, and less drainage were found in the groups that underwent TXA (Group 2 and 3) compared to the group where only a tourniquet was applied (Group 1), and there was a statistically significant difference in all of these evaluation criteria. Unlike other studies in the literature, there was no patient group in this study where the tourniquet was not applied. Therefore, it is necessary to consider this difference when comparing it with other studies. In the present study, the use of TXA with tourniquets has been shown to reduce blood loss and drainage amount. A patient group (Group 4), in which the duration of the tourniquet application was limited, was also taken into consideration. Although there was a statistically significant difference between Group 4 and Group 1 in terms of the maximum Hct decrease and drainage amount, no difference was found between other groups. It was seen that longterm tourniquet use did not have a significant effect in terms of reducing bleeding compared to short-term use. However, it was found that tourniquet use of limited duration with TXA was more effective when compared to cases where TXA was not used.

In addition to the effective use of tranexamic acid, its form of application and dosage are also important [23]. In a compilation study published by Brusalis et al. [24] in 2018 in reference to the randomized controlled prospective study of Huang et al. [2], it was stated that for the use of TXA to be more effective and in order to increase its routine application, it is necessary to determine the optimum methods of administration and doses. In a meta-analysis conducted in 2017, patients, who underwent total hip and total knee arthroplasty, were evaluated. There was no difference between topical and IV TXA administration in terms of transfusion amount and safety. Given the maximum decrease in hemoglobin level, IV administration was shown to be more advantageous [25]. Oral TXA administration was also shown to be effective in a systematic compilation and meta-analysis involving 608 patients [26]. In a prospective randomized clinical study conducted in 2018, there was no difference between oral and IV administration in terms of $\mathrm{Hb}$ and Hct decrease, blood loss, inflammatory, and fibrinolytic response [27]. In another meta-analysis conducted in 2018, it was emphasized that there was no difference between oral administration and IV administration, and oral use might be preferred due to ease of administration and "cost-benefit superiority" [28]. In a randomized controlled study comparing intra-articular, intravenous, and combined administration, intra-articular, and IV-combined administration was shown to be more effective than other methods in reducing blood loss [29]. In the present study, there was no difference between the group where TXA was administered intraarticularly and the group where TXA was applied intravenously in terms of $\mathrm{Hb}$ and Hct decreases, while the amount of drained blood was significantly lower in the group where TXA was administered intraarticularly compared to the group where TXA was applied intravenously. The amount of drainage in the intra-articular group was found to be statistically significantly lower than all other groups. This situation can be interpreted as the use of local intraarticular tranexamic acid in the knee limiting the bleeding within the knee by forming a hematoma. This may cause clogging of the drain and less drainage compared to other groups. Also the hematoma-preventing properties of the drains used should be taken into consideration.

Discussions about the most appropriate dose as well as the preferred method of administration for TXA continue in the literature [23]. In a study conducted in 2016, a single preoperative dose of $30 \mathrm{mg} / \mathrm{kg}$ TXA (2.5g maximum) resulted in the need for less transfusion in patients with elective primary hip and knee arthroplasty compared to lower doses [22]. In a study by Tzatzairis et al. [22], administration of 15 $\mathrm{mg} / \mathrm{kg}$ IV TXA with 3 doses (during induction, at the $3^{\text {rd }}$ and $6^{\text {th }}$ hour) was shown to be more effective than one or two doses. In a study conducted with 175 pa- 
tients in 2019, in addition to the patients in the placebo group, there were those who were administered a preoperative single dose of IV $20 \mathrm{mg} / \mathrm{kg}$, and those who received IV TXA for a total of six times (a total of $6 \mathrm{~g}$ maximum) within the first 24 hours after induction, with the least loss found to be in the six-dose group when these were evaluated in terms of latent blood loss [22]. A dose comparison was not intended in the present study. However, it was found that the best result in the study groups was to apply $2 \mathrm{~g}$ of TXA into the joint immediately after the joint capsule was closed.

In addition to the use of tranexamic acid, another issue is the duration of tourniquet use in total knee arthroplasty surgeries. There is no consensus in the literature on this subject. In a study by Li et al. [30], it was shown that different tourniquet durations did not create a difference in the amount of bleeding during surgery and the need for postoperative transfusion [30]. In another study published in 2020, it was found that short-term tourniquet use with TXA application led to a reduction in $\mathrm{Hb}$ and transfusion requirement, and these patients had less thigh pain and a shorter length of hospital stay compared to patients in whom a long-term tourniquet was applied.

Similarly, in the present study, there was a difference in the amount of bleeding only in the group of patients (Group 4), who had a tourniquet only during the cement application with IV TXA compared to the group that did not undergo TXA. However, no significant difference was seen between Group 2 and Group 4. Short term tourniquet application did not cause any further bleeding. Besides, it was seen that the duration of hospital stay was shortest in the patient group (Group 4) undergoing short-term tourniquet application. In conclusion, the present study shows that shortterm tourniquet application together with TXA is an effective method. Studies to be conducted in large series and standard patient groups will be able to provide more precise information on this subject.

\section{Limitations}

This study has some limitations. The number of patients was limited due to the retrospective nature of the study and the breadth of the exclusion criteria used in order to facilitate standardization of the patient groups. Nevertheless, when the patients were divided into groups, the number of patients was found to be sufficient to make a statistically significant difference. However, multicenter studies in large series, will result in the availability of more comprehensive information. Since there was no patient group in which a tourniquet was not used in the current clinical practice, no such control group could be created. Different application methods were compared. However, different drug dose effects should be evaluated using the data in this study. The present study can serve as a basis for similar studies.

\section{CONCLUSION}

In conclusion, the use of TXA was shown to lead to a reduction in $\mathrm{Hb}$ and Hct, the amount of blood drained after surgery, and the length of hospital stay. The lowest $\mathrm{Hb}$ decrease was seen in the group where intra-articular TXA was applied and the lowest length of hospital stay in the group where the short-term tourniquet was applied. Prospective studies using different drug doses and larger series will provide clearer inferences in this regard.

\section{Authors' Contribution}

Study Conception: MOK, KB, MBG; Study Design: MOK, AM, KB; Supervision: MOK, AM, MBG; Funding: MOK, AM, MBG; Materials: MOK, KB, MBG; Data Collection and/or Processing: MOK, AM, $\mathrm{KB}$; Statistical Analysis and/or Data Interpretation: MOK, AM, KB, MBG; Literature Review: MOK, AM, KB; Manuscript Preparation: MOK, AM, KB and Critical Review: MOK, AM, KB, MBG.

\section{Ethical approval}

Approval was obtained from the ethics committee of Ankara University. The procedures used in this study adhere to the tenets of the Declaration of Helsinki.

\section{Conflict of interest}

The authors disclosed no conflict of interest during the preparation or publication of this manuscript.

\section{Financing}

The authors disclosed that they did not receive any grant during conduction or writing of this study. 


\section{REFERENCES}

1. Lei Y, Xie J, Huang Q, Huang W, Pei F. Additional benefits of multiple-dose tranexamic acid to anti-fibrinolysis and anti-inflammation in total knee arthroplasty: a randomized controlled trial. Arch Orthop Trauma Surg 2020;140:1087-95.

2. Huang Z, Xie X, Li L, Huang Q, Ma J, Shen B, et al. Intravenous and topical tranexamic acid alone are superior to tourniquet use for primary total knee arthroplasty: a prospective, randomized controlled trial. J Bone Joint Surg Am 2017;99:205361.

3. Huang ZY, Pei FX, Ma J, Yang J, Zhou ZK, Kang PD, et al. Comparison of three different tourniquet application strategies for minimally invasive total knee arthroplasty: a prospective nonrandomized clinical trial. Arch Orthop Trauma Surg 2014;134:561-70.

4. Sehat KR, Evans R, Newman JH. How much blood is really lost in total knee arthroplasty?. Correct blood loss management should take hidden loss into account. Knee 2000;7:151-5.

5. Rosencher N, Kerkkamp HE, Macheras G, Munuera LM, Menichella G, Barton DM, et al. Orthopedic surgery transfusion hemoglobin European overview (OSTHEO) study: blood management in elective knee and hip arthroplasty in Europe. Transfusion 2003;43:459-69.

6. Ye W, Liu Y, Liu WF, Li XL, Fei Y, Gao X. Comparison of efficacy and safety between oral and intravenous administration of tranexamic acid for primary total knee/hip replacement: a metaanalysis of randomized controlled trial. J Orthop Surg Res 2020;15:21.

7. Taneja A, El-Bakoury A, Khong H, Railton P, Sharma R, Johnston $\mathrm{KD}$, et al. Association between allogeneic blood transfusion and wound infection after total hip or knee arthroplasty: a retrospective case-control study. J Bone Jt Infect 2019;4:99-105.

8. Sharqzad AS, Cavalheiro C, Zahar A, Lausmann C, Gehrke T, Kendoff D, et al. Blood loss and allogeneic transfusion for surgical treatment of periprosthetic joint infection: a comparison of one- vs. two-stage exchange total hip arthroplasty. Int Orthop 2019;43:2025-30.

9. Sandri A, Mimor BF, Ditta A, Finocchio E, Danzi V, Piccoli P, et al. Perioperative intravenous tranexamic acid reduces blood transfusion in primary cementless total hip arthroplasty. Acta Biomed 2019;90(1-S):81-6.

10. Wang K, Ni S, Li Z, Zhong Q, Li R, Li H, et al. The effects of tourniquet use in total knee arthroplasty: a randomized, controlled trial. Knee Surg Sports Traumatol Arthrosc 2017;25:284957.

11. Ozkunt O, Sariyilmaz K, Gemalmaz HC, Dikici F. The effect of tourniquet usage on cement penetration in total knee arthroplasty: A prospective randomized study of 3 methods. Medicine (Baltimore) 2018;97:e9668.

12. Dennis DA, Kittelson AJ, Yang CC, Miner TM, Kim RH, Stevens-Lapsley JE. Does tourniquet use in TKA affect recovery of lower extremity strength and function? A randomized trial. Clin Orthop Relat Res 2016;474:69-77.

13. Zhou K, Ling T, Wang H, Zhou Z, Shen B, Yang J, et al. Influence of tourniquet use in primary total knee arthroplasty with drainage: a prospective randomised controlled trial. J Orthop
Surg Res 2017;12:172.

14. Liu PL, Li DQ, Zhang YK, Lu QS, Ma L, Bao XZ, et al. Effects of unilateral tourniquet used in patients undergoing simultaneous bilateral total knee arthroplasty. Orthop Surg 2017;9:180-5.

15. Fan Y, Jin J, Sun Z, Li W, Lin J, Weng X, et al. The limited use of a tourniquet during total knee arthroplasty: a randomized controlled trial. Knee 2014;21:1263-8.

16. Ejaz A, Laursen AC, Kappel A, Laursen MB, Jakobsen T, Rasmussen S, et al. Faster recovery without the use of a tourniquet in total knee arthroplasty. Acta Orthop 2014;85:422-6.

17. Stowers MDJ, Aoina J, Vane A, Poutawera V, Hill AG, Munro JT. Tranexamic acid in knee surgery study: a multicentered, randomized, controlled trial. J Arthroplasty 2017;32:3379-84.

18. Fillingham YA, Kayupov E, Plummer DR, Moric M, Gerlinger TL, Della Valle CJ. The James A. Rand young investigator's award: a randomized controlled trial of oral and intravenous tranexamic acid in total knee arthroplasty: the same efficacy at lower cost? J Arthroplasty 2016;31(9 Suppl):26-30.

19. Wu G, Mazzitelli BA, Quek AJ, Veldman MJ, Conroy PJ, Caradoc-Davies TT, et al. Tranexamic acid is an active site inhibitor of urokinase plasminogen activator. Blood Adv 2019;3:729-33.

20. Morales Santias M, Mas Martinez J, Sanz-Reig J, Martinez Gimenez E, Verdu Roman C, Bustamante Suarez de Puga D. Topical tranexamic acid in cemented primary total knee arthroplasty without tourniquet: a prospective randomized study. Eur J Orthop Surg Traumatol 2020;30:1003-8.

21. Meng Y, Li Z, Gong K, An X, Dong J, Tang P. Tranexamic acid reduces intraoperative occult blood loss and tourniquet time in obese knee osteoarthritis patients undergoing total knee arthroplasty: a prospective cohort study. Ther Clin Risk Manag 2018;14:675-83.

22. Tzatzairis T, Drosos GI, Vogiatzaki T, Tilkeridis K, Ververidis A, Kazakos K. Multiple intravenous tranexamic acid doses in total knee arthroplasty without tourniquet: a randomized controlled study. Arch Orthop Trauma Surg 2019;139:859-68.

23. van der Merwe JM, Mastel MS. Controversial topics in total knee arthroplasty: a five-year update (part 2). J AAOS: Glob Res Rev 2020;4:e19.00048.

24. Brusalis CM, Bostrom MPG, Richardson SS. Has tranexamic acid in total knee arthroplasty made tourniquet use obsolete? HSS J 2018;14:338-40.

25. Xie J, Hu Q, Huang Q, Ma J, Lei Y, Pei F. Comparison of intravenous versus topical tranexamic acid in primary total hip and knee arthroplasty: an updated meta-analysis. Thromb Res 2017;153:28-36.

26. Guo P, He Z, Wang Y, Gao F, Sun W, Guo W, et al. Efficacy and safety of oral tranexamic acid in total knee arthroplasty: a systematic review and meta-analysis. Medicine (Baltimore) 2018;97:e0587.

27. Cao G, Xie J, Huang Z, Huang Q, Chen G, Lei Y, et al. Efficacy and safety of multiple boluses of oral versus intravenous tranexamic acid at reducing blood loss after primary total knee arthroplasty without a tourniquet: a prospective randomized clin- 
ical trial. Thromb Res 2018;171:68-73.

28. Han X, Gong G, Han N, Liu M. Efficacy and safety of oral compared with intravenous tranexamic acid in reducing blood loss after primary total knee and hip arthroplasty: a meta-analysis. BMC Musculoskelet Disord 2018;19:430.

29. Zhang YM, Yang B, Sun XD, Zhang Z. Combined intravenous and intra-articular tranexamic acid administration in total knee arthroplasty for preventing blood loss and hyperfibrinolysis: a randomized controlled trial. Medicine (Baltimore) 2019;98:e14458.

30. Li Y, Lu M, Tian H, Li ZJ, Zhang K. [Effect of different tourniquet releasing strategy on blood loss in total knee arthroplasty]. Zhonghua Yi Xue Za Zhi 2017;97:3219-24. [Article in Chinese] 